humanidade, da universalidade que precisam ser constantementes sublinhados, constantemente afirmados na prática cotidiana de todo mundo". Sim, temos uma responsabilidade histórica para com a sociedade gaúcha e a sociedade brasileira. Nós ajudamos em grande parte a construir a consciência republicana e democrática deste Estado e deste país. Esta é uma missão a que não podemos nos furtar, a par da excelência acadêmica do ensino, da pesquisa e da extensão.

Quero finalizar essas rápidas palavras para dizer da emoção e do agradecimento, da emoção pessoal como Diretor e do agradecimento da Faculdade de Direito às entidades que hoje nos homenageiam, às entidades profissionais $\mathrm{e}$ culturais na área jurídica que hoje nos homenageiam nesta noite.

Gostaria de expressar igualmente um agradecimento à sociedade gaúcha pela receptividade com relação a nossa comemoração, pelo carinho com que está sendo acolhida esta comemoração, para todos surpreendente. Sinceramente, nós da Faculdade de Direito não esperávamos tanta receptividade e tanto carinho, talvez porque subestimássemos a importância de nossa tradição, de nossa longa folha de serviços prestados ao Estado e ao país. Creio que é um reconhecimento que nos impulsiona, nos incentiva, nos potencializa para enfrentar as dificul- dades e os desafios do futuro, sem esquecer as agruras do presente. Sim, a Universidade Pública, em especial a Universidade Pública federal, vive um momento de intensas dificuldades. Universidade essa que não é simplesmente a construção deste ou daquele governo, mas é um patrimônio construído por sucessivas gerações e hoje seriamente ameaçado. Mas seguramente resistiremos nesta Faculdade de Direito como já o fizemos em muitos outros momentos. Relembro ainda, na segunda metade dos anos 60, a resistência representada pela Faculdade de Direito em face da famigerada reforma universitária, em face da tentativa de fragmentação da instituição universitária. Aqui faço minhas homenagens ao dr. Ruy Cirne Lima, então Diretor da Faculdade, com quem tive a oportunidade de conviver como Presidente do Centro Acadêmico André da Rocha. Nós sustentaremos sempre a luta pela Universidade Pública, preservando ao mesmo tempo a excelência do ensino, a qualidade da pesquisa e da extensão. E como Universidade Pública que o é, será também sempre um espaço público para o debate franco e aberto, pluralista e democrático, conforme aquele espírito de tolerância que marca a sua trajetória, dos grandes temas e questões nacionais e internacionais que angustiam a humanidade e a civilização neste alvorecer do próximo século.

Muito obrigado.

\section{Reflexões de um antigo aluno de Hannah Arendt sobre o conteúdo, a recepção e o legado de sua obra, no 250 aniversário de sua morte}

\author{
Celso Lafer
}

Li. $-\mathrm{I}-$ obra de Hannah Arendt (1908-1975) vêm crescendo continuamente. Atualmente, a irradiação dos temas centrais de sua reflexão é muito mais significativa do que quando estava viva e fui seu aluno de pós-graduação, na Universidade de Cornell nos EUA, em 1965.

Naquela época, ela era uma personalidade conhecida, mas controvertida, presente n vida universitária e intelectual norte-americana, tendo já transposto os circuitos acadêmicos, graças ao fundamental livro, de 1951, sobre o totalitarismo. Era, no entanto, vista com suspeita pela esquerda, por conta da qualificação, não apenas do nazismo, mas também do stalinismo como vertente de um ti po inédito de regime de dominação, caracterizado pela ubiqüidade do medo, instrumentado na organização burocrátca de massas e sustentado pelo emprego do terror e da ideologia. Tinha além disso adquirido notoriedade adicional por conta das vivas polêmicas suscitadas pelo relato do processo Eichmann e pelo conceito da "banalidade do mal", por ela cunhado em livro da década de 60 sobre o assunto. No livro, discutiu o descompasso entre a enormidade do crime do holocausto e a opaca irrelevância da personali-

dade do burocrata que o administrou com terrí vel eficiência.

Hannah Arendt era admirada por seu resgate teórico do papel da ação no espaço público, mas considerada por muitos como defensora nostálgica e anacrônica da polis grega e da herança clássica. Era percebida como pensadora idiossincrática que admirava a esperança do "novo", inerente ao fenômeno revolucionário, e ao mesmo tempo advertia sobre os seus descaminhos; que salientava, de um lado, a relevância da autoridade como categoria política, e de outro sublinhava o significado da desobediência civil como forma válida da resistência à opressão e de recuperação da obrigação política.

Em síntese, não havia consenso em torno da pertinência da sua obra para o entendimento do mundo contemporâneo, e prevalecia razoável desconforto em relação a uma pessoa que não se enquadrava nos cânones políticos usuais (esquerda/direita; liberal/conservadora, etc.), nem era facilmente identificável no âmbito das disci plinas acadêmicas (Filosofia, Teoria Política, História, etc.) "I somehow don't fit", observou a própria Hannah Arendt num importante colóquio sobre a sua obra realizado em novembro de 1972 . 


\section{- II -}

25 anos após a morte de Hannah Arendt, em New York em 4 de dezembro de 1975, continuam vivas as discussões sobre a sua obra inclusive no Brasil. Estas discussões retêm uma variedade de perspectivas. Há os que apontam o que nela há de pós-moderno; outros, como Margaret Canovan, que sublinham os seus vínculos com a clássica tradição do pensamento político republicano. Há os que, como Paolo Flores d'Arcais, a qualificam como expressão de um existencialismo libertário. Alguns realçam a presença de Nietzsche e Heidegger, deles discrepando os que preferem chamar a atenção para o legado de Aristóteles e Kant. Persistem leituras neo-conservadoras, às quais continuam se contrapondo, nas trilhas abertas por Claude Lefort e Castoriadis, as de esquerda, de índole e de resistência revolucionária, que também mencionam o que Hannah Arendt deve à herança marxista. A elas se agregaram leituras feministas. Em síntese, a obra de Hannah Arendt permanece instigante e é vista como um extraordinário ativo intelectual, porém num contexto que mudou radicalmente.

A mudança do contexto provém da criação de um consenso intelectual em torno da pertinência de seu legado para o entendimento do mundo contemporâneo. É por esse motivo que a cada ano, nos mais diversos quadrantes culturais, vêm surgindo interpretações novas e, como mencionei, por vezes bastante contrastantes de sua obra. Também os seus inéditos e os vários volumes de sua correspondência vêm sendo publicados, e discutidos com muito interesse. Num certo sentido, pode-se dizer que ela está se convertendo num "clássico" do mundo contemporâneo, posto que a sua obra, ao lidar com a condição do ser humano no século $\mathrm{XX}$, responde aos critérios de persistência do clássico apontado por Bobbio: cada vez mais é vista como interpretação autêntica da época em que viveu; provoca constan- tes leituras e releituras e nos oferece categorias de que nos valemos para compreender a realidade que nos cerca.

O que explica a formação desse consenso e o reconhecimento desta dimensão de "clássico" que atualmente cerca o legado arendtiano?

Em 1982, Elizabeth Young-Bruehl publicou uma admirável biografia de Hannah Arendt. Este livro, que pela qualidade da análise e a abrangência da pesquisa continua sendo fundamental na bibliografia arendtiana, mostra que existem pensadores cujo intelecto nos fascina mas cuja biografia suscita pouco interesse. É o caso de Kant, que Hannah Arendt tanto admirou. Existem personalidades cuja vida é tão fascinante quanto a obra, como é o caso de Malraux, que Hannah Arendt discutiu, ao examinar o seu romance A Condicão Huma na, no meu curso de Cornell sobre as experiências políticas do século XX. A biografia elaborada por Young Bruhel revela que a vida de Hannah Arendt é não só interessante, mas fundamental para compreender a sua obra.

O livro de Young Bruehl é um relato exemplar de como um ser humano lidou com tempos sombrios e, na condição de judia alemã, atravessou, sobreviveu e pensou as catástrofes políticas, os desastres morais e os surpreendentes desenvolvimentos das artes e ciências no século XX. Ao discutir o livro de Young Brueh por ocasião de sua publicação, procurei mostrar como na sua travessia Hannah Arendt elaborou em termos muito próprios, um modo de ver e um modo de ser. São estes dois modo que dão, penso eu, a chave para a compreensão tanto de sua obra quanto do alcance do seu legado.

O método de Hannah Arendt é o que ela absorveu na Universidade alemã onde, no contexto da efervecência e da criatividade da
República de Weimar, foi aluna de Heidegger e Jaspers. Em síntese, a sua formação filosófica calcada no complexo fenomenologia/ existencialismo, é uma parte importante da su maneira de ver o mundo. É a sua tradição como ela diz, numa polêmica e conhecida car ta de 24 de julho de 1963 a Gershom Sholem, a propósito do controvertido livro sobre Eichmann. A correspondência em alemão de Hannah Arendt com Jaspers, publicada postumamente 1985), e assim como a correspondência com Heidegger, recém- publicada em 1999 tem como dimensão subjacente o fio de continuidade de sua tradição. Ela retomou explicitamente esta tradição no final da vida e da experiência de sua travessia intelectual, em livro postumamente publicado, no qual, ao cuidar das diferenças entre o pensar, o querer e o julgar afirmou o pluralismo de The Life of the Mind (1978-1979).

As raizes filosóficas de Hannah Arendt no entanto, não explicam nem o objeto da maior parte de suas análises e investigações, nem o seu modo de ser. Com efeito, a tradição de vida contemporânea, na qual se formou, é a do distanciamento das coisas que separa o filósofo da experiência do mundo. Neste distanciamento, e nos seus equívocos - inclusive os políticos - que teve em Platão um primeiro paradigma, Hannah Arendt não incidiu. Não incidiu porque se viu confrontada com o mun do por força da questão judaica. Ao vivê-la e ao pensar sobre ela foi configurando, as perguntas mais abrangentes, enformadoras de alguns de seus livros fundamentais.

A experiência epistemológica do confronto com a realidade desenvolveu em Hannah Arendt uma aptidão especial para pensar o geral e o seu significado a partir da situação concreta. Daí a originalidade na qual se fundiram no seu percurso o saber haurido na filosofia alemã e o olhar ensejado por sua inserção no mundo histórico-social e pelas vicissitudes de sua vida, no trato de temas e na reelaboração de categorias como a liberdade, a mentira, a violência, o imperialismo, a autoridade, a desobediência civil, a revolução.

A experiência concreta dos dilemas problemas da questão judaica foi para Hannah Arendt, para recorrer a terminologia de Jaspers, uma situação-limite. De 1933- data de sua fuga da Alemanha nazista, depois de ter sido presa por estar coletando documentação sobre antisemitismo - até 1951, quando adquiriu a cidadania norte-americana, ela foi juridicamente uma apátrida. Neste período, morou na França, dedicou-se à imigração de jovens judeus para a Palestina e, com a derrocada francesa, foi internada no campo de Gurs; conseguiu escapar, com o seu segundo marido Heinrich Blücher (o que não aconteceu com o seu amigo Walter Benajmin), via Lisboa, para os Estados Unidos. Viveu, assim, a dura experiência de refugiada, ou seja, de quem , para usar as suas próprias palavras, num artigo de 1943, perdeu o lar e, com ele a familiaridade da vida cotidiana; perdeu a profissão e, desta maneira, a segurança de ter alguma utilidade no mundo; perdeu o uso da língua materna e, com esta privação, a naturalidade das reações e simplicidade dos gestos e a expressão espontânea dos sentimentos.

No contexto desta situação-limite, é compreensível que a questão judaica tenha se tornado o ponto focal do seu pensar político histórico, como disse a Jaspers, logo após a Segunda Guerra Mundial, em carta de $21 \mathrm{de} \mathrm{ja-}$ neiro de 1946. Foi esta situação-limite que fez com que ela tivesse que pensar os acontecimentos pela própria cabeça, sem o apoio de instituições e de tradições consolidadas. Daí uma das características do seu modo de ser. Este, diria eu, expressa-se através da rebeldia crítica do pária consciente - uma categoria que ela elaborou baseada em Bernard Lazare e que se inspira no alcance do pensamento que, com base na experiência própria, tem a coragem individual de 
julgar, sem apoio numa tradição constituída. Heine e Kafka no campo de literatura; Walter Benjamin no da crítica; Rosa Luxemburgo no do socialismo; Bernard Lazare, no do sionismo, sobre os quais Hannah Arendt escreveu com tanta argúcia e compreensão, representam para ela, cada um à sua maneira, a fecunda experiência intelectual da rebeldia crítica do pária consciente, com a qual ela se identifica.

Não há, convém deixar bem claro, na reflexão de Hannah Arendt, o "pariasismo", que como o "obrerismo" seria uma forma de identidade coletiva. Com efeito, para ela, o pensamento enraizado na particularidade e na contingência da experiência vivida é um modo fundamental da abertura do espírito em relação ao mundo, como realçou AnneMarie Roviello. Ela não tem uma perspectiva fixa e o seu olhar é móvel, mas direcionado por um amor mundi. Foi por este motivo que Richard J. Bernstein concluiu o seu livro sobre Hannah Arendt e a questão judaica, indicando que, dentro de uma vertente de tradição judaica, a reflexão arendtiana, que é secular, está voltada para o mundo que Deus criou, não para o Criador.

Em poucas palavras, e para arrematar esta parte do meu argumento, diria que o modo de ver e o modo de ser de Hannah Arendt, a abrangência reflexiva da sua experiência e o amor mundi que a instiga são os elementos que explicam porque com o tempo ela foi sendo reconhecida como um "clássico" do mundo contemporâneo, na acepção acima referida de Bobbio. A sua obra e o seu legado continuam a responder às múlti plas inquietações do nosso tempo. São justamente algumas destas múltiplas inquietações para as quais as suas reflexões oferecem caminhos, que vou a seguir exemplificativamente elencar.

\section{- III -}

Começando pelo mais geral, lembro que a velocidade crescente da inovação tecnológic ção do conhecimento científico uma das facetas mais determinantes da realidade contemporânea. Trata-se de um dos ineditismos do século $\mathrm{XX}$, que se projeta de forma avassaladora para o novo século. É para o significado da ruptura derivada da contínua transposição de barreiras, antes tidas como naturais, que Hannah Arendt chama a nossa atenção no prólogo de The Human Condition, ao afirmar que o Sputnik - o primeiro satélite artificial lançado em 1957 - foi um evento que ultrapassou todos os outros, até mesmo o da desintegração do átomo. Neste mesmo prólogo de um livro de 1958, ela sublinha que a direção do novo conhecimento científico e técnico é uma questão política de primeira grandeza.

A relevância desta questão política é de indiscutível atualidade. Basta mencionar que nesta era de globalização, a dinâmica da inovação tecnológica vem reduzindo o custo dos produtos e, concomitantemente, diminuindo a importância da força do trabalho. Isto coloca de forma incisiva e muito especialmente para as economias emergentes, o problema do destino dos operários. Ora, um dos temas anteci pados por Hannah Arendt em The Human Condition ao cuidar do labor e da automação, que então se iniciava, é, como ela diz, a perspectiva de "uma sociedade de trabalhadores sem trabalho, isto é, sem a única atividade que lhes resta Certamente nada poderia ser pior" (Hannah Arendt, The Human Condition, Chicago; Chicago University Press, 1958,pp.4-5).

A descartabilidade dos seres humanos do ponto-de-vista da produção é uma das razões pelas quais, hoje, os homens não estão à vontade e em casa no mundo. Não estar à vontade e em casa no mundo é um dos temas fortes da reflexão arendtiana. Compreender as situações que levam a isso e buscar caminhos para recuperar a constitutio libertatisé uma das marcas fundamentais do legado intelectual de Hannah Arendt.

A persistência de "displaced people" não se esgota na problemática da produção contemporânea de bens e serviços, anteci pada po Hannah Arendt. Continua na ordem do dia em função das realidades das fronteiras nacionais, o drama dos migrantes, dos refugiado econômicos e políticos que hoje se multi plican e se espalham pelo planeta sem poder usufrui de uma kantiana hospitalidade universal, porque são "sans-papiers". Trata-se aqui do tema arendtiano do "direito a ter direitos", examina do mais amplamente no capítulo 9 do The Origins of Totalitarianism, que permanece como "tema global" da vida internacional. Com efeto, persiste o problema da falta de um víncul efetivo com uma ordem jurídica, num mundo globalizado mas ainda organizado de maneira inter-estatal, que empurra um sem número de seres humanos para a inumanidade de um estado de natureza hobbesiano.

Os temas da secessão de estados, da nacionalidades, das minorias, - lingüísticas, rel giosas e nacionais, - das "raças" e da "limpeza étnica", discutidos por Hannah Arendt em The Origins of the Totalitarianism, permanecem na agenda. Na verdade, afloraram com novo vigor depois da desagregação da União Soviética e do fim da bi polaridade, indicando com clare$\mathrm{za}$ os perigos do inter homines esse, em contextos que favorecem, sem maiores limitações, em sociedades de massa, a plena "sublevação dos particularismos", para valer-me de uma formulação de Octavio Paz

O regime totalitário, caracterizado na análise arendtiana pela ubiqüidade do medo e sustentado pelo emprego do terror e da ideologia, não desapareceu como possibilidade histórica e risco para a vida das pessoas com a derro- cada do nazismo e o degelo pós-Stalin. Ele fo recriado no Terceiro Mundo, por exemplo, por Pol Pot na Campuchéia (Camboja), nos anos 70 , e não se deve esquecer que a revolução cultural de Mao na China foi um movimento totalitário, num regime que aparentemente caminhava, com as "cem flores", para um certo pluralismo. Em contraposição, a Revolução Húngara de 1956, como apontou na ocasião Hannah Arendt, foi um evento que assinalou através do inesperado e do criativo da ação política, motivado pelo gosto da liberdade e pelo desejo da verdade despojado de ideologia, a possibilidade de romper rotinas de dominação consolidadas, mesmo num regime ainda muito marcado por traços totalitários. Ao pensar o significado deste evento, Hannah Arendt antecipou, muito mais do que os estudiosos que trabalharam com tendências históricas, forças sociais e estatísticas, a queda do muro de Berlim e a desagregação da URSS e do seu sistema de poder.

As suas reflexões sobre a Revolução Húngara, foram retomadas em outro plano conceitual em The Human Condition, na análise da criatividade da ação e na esperança que provém da natalidade - que para ela é a categoria central da política, em oposição à meditatio mortis da tradição metafísica. Também em On Revolution $(1963,1965)$, a relevância da autoorganização popular, por ela apontada como aspecto da maior importância da Revolução Húngara, é aprofundada na discussão do sistema de conselhos (town-halls; rätes; soviets etc) como um componente positivo da experiência revolucionária.

Estas vertentes da visão arendtiana adquirem um foco muito preciso nas suas análise subsequentes sobre as diferenças entre poder $\mathrm{e}$ violência. $\mathrm{Na}$ sua análise do poder, ela desloca o foco da tradicional temática do seu emprego e aplicação para o da sua criação e manutenção, como bem realçou Habermas. Para ela, o 
poder - que é inerente a qualquer comunidade política - resulta da capacidade humana para agir em conjunto, o que, por sua vez, requer o consenso de muitos quanto a um curso comum de ação. Assim, no Brasil, o movimento das "diretas-já" é um excelente exemplo de ação conjunta geradora de poder, que foi na década de 80 um ingrediente chave a promover o término do regime militar e o advento da redemocratização.

Para Hannah Arendt, poder e violência são termos opostos: a afirmação absoluta de um dos termos significa a ausência do outro. Em sintese: a violência destrói o poder, não o cria. Esta lição arendtiana para nós na América do Sul, que vivemos o que foram as conseqüências da luta armada e da guerrilha, é um aspecto importante da atualidade do seu legado.

No entanto a violência destrutiva do poder está, como explicita, muito presente na vida do século XX. Ela a explica pela severa frustração da faculdade de agir no mundo contemporâneo, que tem suas raízes na burocratização da vida pública, na vulnerabilidade dos grandes sistemas e na monopolização do poder que seca as suas fontes criativas. A carência da capacidade de agir em conjunto é um convite à violência. Aqueles que perdem esta capacidade, sentindo-a escapar de suas mãos - seja na perspectiva ex parte principis, seja na ex parte populi -dificilmente resistem à tentação de substituir pela violência o poder que está desaparecendo. Segundo ela, o acréscimo da brutalidade policial, por exemplo, freqüentemente é conseqüência da ineficiência generalizada da polícia.

Uma das razões da violência, - que é o que converte os engagés em enragés, - é a palavra que não revela a imprescindivel transparência do espaço público, mas a esconde na opacidade. Daí a idéia de arrancar, pela violência, as máscaras da hi pocrisia dos governantes. Es- tas considerações de Hannah Arendt em On Violence (1969-1970) foram posteriormente inseridas na coletânea de ensaios Crisis of the Republic (1972). Dizem respeito também ao contraste, para usar a fórmula de Bobbio, entre os ideais democráticos e a "democracia-real". Este contraste adquire muita nitidez, para continuar com Bobbio, com a força do poder invisível dos arcana imperii, do "sotto governo" e do "cri pto governo". É disso que Hannah Arendt trata em Crisis of the Republic ao examinar a mentira na politica, a preocupação com o imagemaking e, - como deflui do ensaio inserido na $2^{\mathrm{a}}$ edição de Between Past and Future, - a imprescindibilidade da verdade factual, como a base primeira da verdade na política. A atualidade do seu legado neste campo não requer maiores elaborações. Basta, inter alia, mencionar os dilemas da vida democrática inerentes às relações entre a mídia e a política, e os temas da mani pulação da opinião pública e da invasão das "relaçōes públicas" na vida política que Hannah Arendt apontou em um de seus últimos textos, o "Home to Roost: A bicentennial address" (1975).

A importância política da verdade factual adquire relevância adicional no que tange ao alcance e à justiça da relação entre narrativa testemunho. Só se lida, a posteriorie apropriadamente com as conseqüências de dark times como aponta Hannah Arendt no seu ensaio sobre a escritora Isac Dinensen, narrando o que se passou. As dores podem ser suportadas, se postas numa "história" que revela o alcance do ocorrido, que do contrário, permanece como uma seqüência intolerável de meros acontecimentos. Neste contexto da dor, a relação entre ação, estória e história, realçada por Paul Ricoeur na sua análise de The Human Condition, explicita-se no contar. Este contar - que diz respeito ao poder redentor da narrativa como aponta Seyla Benhabib permite o acordo e a reconciliação, ao revelar o sentido, sem incidir no erro de defi- ni-lo (Hannah Arendt, Men in Dark Times, N.York, Harcourt, Brace,World, 1968,pp.104105).

O relatório Sábato na Argentina e o Brasil. nunca mais da Comissão Justiça e Paz de São Paulo, sobre as torturas em regimes autoritários ou as Comissões de verdade e reconciliação, criadas na África do Sul para lidar com o que foi o apartheidsão exemplos da importância daquilo que é com justiça narrado.

O que diz Hannah Arendt na sua análise do processo Eichmann sobre a tipificação do genocídio como crime contra a humanidade, porque representa uma contestação frontal à condição humana da pluralidade e da diversidade, parece-me lamentavelmente atual, em função dos surtos de xenofobia, dos conflitos tribais, dos fundamentalismos religiosos e da conseqüente força da intolerância, presente no mundo contemporâneo. Também entendo que a sua avaliação de que o anti-semitismo explica a escolha das vítimas do holocausto, mas não a natureza sem precedentes do crime do genocídio é relevante no cenário dos riscos contemporâneos, que vão muito além dos persistentes perigos do anti-semitismo.

Aponto igualmente que a experiência judaica, por ela discutida, de privilegiar a memória da perseguição em detrimento da história, à luz de uma estratégia de sobrevivência, baseada numa dissociação do mundo, pode levar à falta de visão política. Os textos arendtianos dos anos 40 de crítica às vertentes majoritárias do sionismo, que não levavam em conta as realidades do mundo árabe, são pertinentes para o entendimento do percurso e das vicissitudes histórico-políticas do Estado de Israel.

Deste passeio pelos temas do legado arendtiano fica claro o alcance epistemológico por ela proposto, do julgar com faculdade do Espírito, distinta do pensar e do querer. Tanto nas primeiras aproximações ao tema quanto nas postumamente publicadas Lectures on Kant's Political Philosophy (1982), Hannah Arend explora e destaca a relevância do juízo reflexivo, como modo de lidar com o específico sem perder o horizonte do seu significado geral. Por isso, o julgar é uma faculdade indispensável para a ação política na modalidade do juízo prospectivo e, para o pensador e o historiador. na modalidade do juízo retrospectivo, numa época como a nossa, na qual a ruptura entre o passado e o futuro tornou os "universais" fugidios. O julgar é assim o nexo entre a teoria e a prática e a condição da possibilidade do pensar e do agir without bannisters. É por meio do juízo reflexivo que Hannah Arendt extrai e alcança das especificidades exemplares dos acontecimentos uma universalidade de reflexão que é a marca dos fermenta cognitionis da atualidade de seu legado intelectual.

Em síntese, e para finalizar, creio que os pontos que aflorei neste texto - e muitos outros poderiam ser realçados se não fossem as limitações do espaço - são suficientes para substanciar a afirmação de que Hannah Arendt é efetivamente um "clássico" do século XX. 